\title{
Ureteroscopic Management of Ureteral Calculi: Pneumatic versus Holmium: YAG Laser Lithotripsy
}

\author{
Sarwar Noori Mahmood, Diar Hameed Bajalan \\ Department of Surgery, School of Medicine, University of Sulaimania, Iraq \\ Email: sarwar.mahmood@univsul.ed.iq
}

Received 30 January 2016; accepted 19 March 2016; published 22 March 2016

Copyright (C) 2016 by authors and Scientific Research Publishing Inc.

This work is licensed under the Creative Commons Attribution International License (CC BY). http://creativecommons.org/licenses/by/4.0/

\section{Open Access}

\section{Abstract}

Background: Among various intracorporeal lithotripters, pneumatic lithotripter has become the widely used tool for the treatment of urinary stones. Recently the holmium: YAG laser has been used with a wide range of potential urological applications, including intracorporeal lithotripsy of urinary calculi. Purpose: Compare the effectiveness and complications of treatment for ureteric stones between holmium laser lithotripsy and pneumatic lithotripsy. Material and Methods: Comparison of 100 patients presented with ureteric stones, group one (50) of whom were treated with pneumatic lithotripsy and group two (50) with holmium laser was done and the effectiveness and complications of both were analyzed. Results: There was no difference in patient age, sex, stone size and location of stones between the two groups. The immediate stone free rates were $88 \%$ in the holmium: YAG group and $66 \%$ in the pneumatic lithotripsy group $(p<0.05)$. The four weeks stone free rates were $98 \%$ and $94 \%$ respectively $(p=0.07)$. The mean \pm SD operative time in the holmium: YAG group $(40 \pm 26 \mathrm{~min})$ was shorter than those with pneumatic lithotripsy group $(60 \pm$ $40 \mathrm{~min}$ ). Postoperative stay in hospital was less than 24 hours in holmium: YAG group (70.4\%) and shorter than those for pneumatic group $(29.6 \%)(p<0.002)$. Post treatment complications such as ureteral perforation were encountered in only two patients who underwent pneumatic lithotripsy. Other complications, such as mucosal injury, ureteral perforation and postoperative fever; there was no statistically significant difference between the two groups. While light hematuria was found more frequently in the pneumatic group (14\%) in comparison to laser group $(12 \%)(p=0.02)$. On the other hand, the overall complication rates between the two groups was statistically significant $(8 \%)$ laser group vs. $(32 \%)$ pneumatic group $(p=0.003)$. Conclusions: Holmium: YAG laser lithotripsy was associated with shorter operation time and postoperative hospitalization period. These data suggest that holmium: YAG lithotripsy was safe and more effective than Pneumatic lithotripsy in the aspect of immediate stone free rate. We believe that holmium: YAG is an excellent treatment modality for managing ureteral calculi. 


\section{Keywords}

\section{Ureteral Calculus, Ureteroscopy, Lithotripsy, Laser}

\section{Introduction}

Technical advancement in endoscope design and miniaturization have allowed surgeons to access calculi throughout the collecting system and regards as a gold standard for management of ureteral stones [1]. The stone free rates with the use of semi-rigid or flexible ureteroscopes have increased to $90 \%-100 \%$ for the distal ureteral calculi and to $74 \%$ for proximal ureteral calculi [2]. Moreover an impressive $95 \%$ of the patients were stone free rate after a single procedure [3]. Stone disintegration through a rigid ureteroscope can be achieved with in situ lithotripsy. The spectrum of lithotripters includes: Ultrasonic lithotripsy, electrohydrolic lithotripsy, pneumatic lithotripsy and laser lithotripsy [4]. Pneumatic and holmium: YAG laser lithotripsies are commonly used in majority of urology centers and both reported favorable outcomes [5].

The holmium laser is one of safest, most effective and most versatile intracorporeal lithotripters [6] [7]. And become one of the most widely accepted for this purpose as compared to ultrasonic, pneumatic lithotripter [8]. It has a wide range of endoscopic applications, and has demonstrated effectiveness in clearing stones of all compositions [9]. The holmium: YAG laser is transmittable via flexible fibers which vary in diameter from 200 to $360 \mu \mathrm{m}$. The thermal effect produced by holmium: YAG laser's pulses are due to formation of plasma bubble which acts on stone without retropulsion [10]. The zone of thermal injury associated with laser ablation ranges from $0.5-1.0 \mathrm{~mm}$ [11]. Therefore subsequent injury of the ureter is unlikely to happen as long as the lithotripsy is performed under direct vision. Using laser lithotripters the trauma to the urothelial mucosa is usually less compared to the other lithotripters [12]. The lithoclast lithotripsy fragments calculi with a mechanism similar to that of a pneumatic jackhammer. Compressed air propels a small projectile against the probe, causing the probe to oscillate back and forth at frequency of 12 cycles per second. Fragmentation occurs as the probe tips repeatedly impact the stone [13] [14]. The advantages of ballistic lithotripsy are their relatively low cost and low maintenance. The disadvantages of ballistic devices include the rigid nature of the technology, which requires ureteroscopes or nephroscopes with straight working channels, with a relatively high rate of stone retropulsion [15]. Furthermore, lithoclast lithotripsy fragments the calculi into multiple chunks that need to be basketed and removed [16].

Aim of this study is to compare the efficacy and safety of holmium: YAG laser with the pneumatic lithotripter in the treating ureteral calculi.

\section{Patients and Methods}

A prospective study including a total of one hundred patients presented with ureteral stones, who were candidate for transuretral lithotripsy, they were assigned into two groups (50 patients in each group) using a prospective comparative study in a period between November 2013 and August 2014 at urology department sulaymania teaching hospital.

Patients in both groups (group one and group two) underwent transuretral lithotripsy using pneumatic and Holmium: YAG laser, respectively. Informed consents were obtained from all the patients. Patients were included when they had single or multiple ureteric stones of different sizes $(7-20 \mathrm{~mm})$, presence of moderate or severe hydronephrosis, failed medical conservative treatment, symptomatic patient and single kidney with ureteric stones or bilateral ureteric stones. Patients with renal anomalies, pelvic or caliceal stones, pregnancy, severe musculoskeletal deformity and history of uncontrolled coagulopathy were excluded from the study. Before the procedure, urine cultures were obtained, and if positive, antibiotics were administered. All of the subjects should have negative urine cultures preoperatively. Patients were assessed by ultrasonography and plain abdominal X-ray (kidney-ureter and bladder), excretory urography before performing transuretral lithotripsy to evaluate stone size and location, non-contrast CT-scan was done when indicated in selected cases to document stone size and location.

All the procedures were done by an $8 \mathrm{Fr}$ semi-rigid Karl storz ureteroscope in both groups, under general or spinal anesthesia after receiving a single shot of prophylactic antibiotic. In laser lithotripsy, holmium: YAG laser 
power ranged from 2.5 watt $(0.5 \mathrm{~J}$ at $5 \mathrm{~Hz})$ to 10 watts $(1.0 \mathrm{~J}$ at $10 \mathrm{~Hz})$ stones were dusted and left for spontaneous clearance. For lithoclast lithotripsy, $1.0 \mathrm{~mm}$ probe was used to fragment the stone with both single and continuous pulses and pressure was set at 2 bars, large stone fragments were removed using either Dormia basket or tripronge forceps and small one left for spontaneous clearance. In order to maintain a clear ureteroscopic view, irrigation was pumped manually and intermittently during the procedure.

After stone fragmentation, final ureteroscopy was performed under direct vision to detect any residual stone or injury to the ureteral wall or adjacent organs. Indwelling ureteral double $\mathrm{J}$ stent of 5-6Fr was placed when indicated and removed after 2 weeks. Urethral catheter (if inserted) was removed 6 hours postoperatively. All the patients were re-evaluated by abdominal ultrasonography and plain abdominal X-ray (Kidney-ureter and bladder) after two weeks and four weeks postoperatively. Demographic characteristics, operation time, lithotripsy time (from the first fire to the stone to the last fire), immediate stone-free rate, after four weeks stone-free rate, hospitalization, and preoperative complication and postoperative complication such as, mucosal injury, ureteral perforation and fever ( $>38 \mathrm{c}$ ); were compared between the two groups. Stone-free status (residual stone fragments $<2$ $\mathrm{mm}$ ) and the stone pushing back were determined intra-operatively.

Data analysis was performed using SPSS software (the Statistical Package for the Social Sciences, Version 19.0) through student's $t$ test and chi-square test for continuous and categorical variables, respectively. A $p$ value less than 0.05 were considered statistically as significant.

\section{Results}

A total of one hundred patients who underwent transuretral lithotripsy were analyzed. The group one patients were managed with pneumatic lithotripsy and group two patients were managed with Holmium: YAG laser in urology department Sulaymania teaching hospitals).

Patients' demographics and clinical characteristics are shown in Table 1. Mean patients' age, male to female ratio, and stone size were similar between the two groups.

Table 2 summarizes operative characteristics, outcomes and complications in both groups. The mean $( \pm \mathrm{SD})$ of the duration of lithotripsy was $(14.7 \pm 2.6)$ minutes in laser group in comparison to $(7.9 \pm 2.2)$ minutes in pneumatic group and this was statistically significant $(p=0.001)$. On the other hand, the mean operative time was shorter in the laser group ( $40 \pm 26$ minutes) in comparison to the pneumatic group (60 \pm 40 minutes), a result was statistically significant $(p=0.033)$.

Moreover, the majority of patients in the laser group stay in hospital $<24$ hours (38 patients $70.4 \%$ ) in comparison to only 16 patients in the pneumatic group $(29.6 \%)$ a finding was statistically significant $(p<0.002)$.

Likewise, the immediate stone-free rate was found in 44 patients (88.0\%) in laser group compared to 31 patients $(62.0 \%)$ in pneumatic group, again a finding which was statistically significant $(p=0.001)$.

On the other hand, the 4 weeks stone-free rate was found in 49 patients (98\%) in laser group, while in pneumatic group was found in 47 patients $(94.0 \%)$ and this result was statistically not significant $(p=0.0732)$.

Migration of Stones occurred only in 5 patients (10.0\%) in pneumatic group. While, there was only one patient

Table 1. Demographic and clinical characteristics of the patients.

\begin{tabular}{|c|c|c|c|}
\hline Variable & $\operatorname{LASER}(\mathrm{n}=50)$ & Pneumatic $(\mathrm{n}=50)$ & $\rho$-value \\
\hline Mean age \pm SD, $y$ & $38.4 \pm 13.2$ & $40.7 \pm 14.5$ & 0.41 (NS) \\
\hline Male, n (\%) & $29(58.0 \%)$ & $27(54.0 \%)$ & 0.309 (NS) \\
\hline Female, n (\%) & $21(42.0 \%)$ & $23(46.0 \%)$ & 0.724 (NS) \\
\hline Previous history of URS, n (\%) & $3(6.0 \%)$ & $7(14.0 \%)$ & 0.834 (NS) \\
\hline $\begin{array}{l}\text { Stone laterality } \\
\text { Right side, n (\%) } \\
\text { Left side, n (\%) }\end{array}$ & $\begin{array}{l}22(44.0 \%) \\
28(56.0 \%)\end{array}$ & $\begin{array}{l}29(58.0 \%) \\
21(42.0 \%)\end{array}$ & 0.624 (NS) \\
\hline Stone size diameter by (mm) & $12.34 \pm 2.6$ & $10.34 \pm 1.2$ & 0.389 (NS) \\
\hline $\begin{array}{l}\text { Stone location } \\
\text { Proximal, n (\%) } \\
\text { Middle, n (\%) } \\
\text { Distal, n (\%) }\end{array}$ & $\begin{array}{l}22(44.0 \%) \\
10(20.0 \%) \\
18(36.0 \%)\end{array}$ & $\begin{array}{l}21(42.0 \%) \\
13(26.0 \%) \\
16(32.0 \%)\end{array}$ & 0.52 (NS) \\
\hline
\end{tabular}


Table 2. Operative characteristics, outcomes and complications.

\begin{tabular}{|c|c|c|c|}
\hline Variable & $\begin{array}{l}\text { LASER } \\
(\mathrm{n}=50)\end{array}$ & $\begin{array}{l}\text { Pneumatic } \\
(\mathrm{n}=50)\end{array}$ & $\rho$-value \\
\hline Complications: & & & \\
\hline Hematuria, n (\%) & $1(2.0 \%)$ & $7(14.0 \%)$ & $0.022(\mathrm{~S})$ \\
\hline Mucosal damage, n (\%) & $1(2.0 \%)$ & $3(6.0 \%)$ & 0.543 (NS) \\
\hline Ureteral perforation, n (\%) & $0(0.0 \%)$ & $2(4.0 \%)$ & 0.423 (NS) \\
\hline Postoperative fever, n (\%) & $2(4.0 \%)$ & $4(8.0 \%)$ & 0.643 (NS) \\
\hline Overall complications rate n (\%) & $4(8.0 \%)$ & $16(32.0 \%)$ & $0.003(\mathrm{~S})$ \\
\hline Migration of stone, n (\%) & $1(2.0 \%)$ & $5(10.0 \%)$ & $0.003(\mathrm{~S})$ \\
\hline Mean \pm SD operation time (min) & $40 \pm 26$ & $60 \pm 40$ & $0.033(\mathrm{~S})$ \\
\hline Mean \pm SD lithotripsy time( min) & $14.7 \pm 2.6$ & $7.9 \pm 2.2$ & $0.001(\mathrm{~S})$ \\
\hline Hospital stays < 24 hr, n (\%) & $38(70.4 \%)$ & $16(29.6 \%)$ & $<0.002(\mathrm{~S})$ \\
\hline Immediate stone-free status, n (\%) & $44(88.0 \%)$ & $31(62.0 \%)$ & $<0.05(\mathrm{~S})$ \\
\hline 4 weeks stone-free status, n (\%) & 49 (98\%) & 47 (94.0\%) & 0.0732 (N.S) \\
\hline $\begin{array}{l}\text { Stone location, SFR } \\
\text { Proximal, n (\%) } \\
\text { Middle, n (\%) } \\
\text { Distal, n (\%) }\end{array}$ & $\begin{array}{c}19 / 22(86.4 \%) \\
8 / 10(80.0 \%) \\
17 / 18(94.4 \%)\end{array}$ & $\begin{array}{c}7 / 21(33.3 \%) \\
9 / 13(69.2 \%) \\
15 / 16(93.7 \%)\end{array}$ & $\begin{array}{c}0.002 \text { (S) } \\
0.308 \text { (NS) } \\
0.456 \text { (NS) }\end{array}$ \\
\hline D.J stent need n (\%) & $22(37.9 \%)$ & $36(62.1 \%)$ & $<0.005$ (S) \\
\hline Dormia basket need, n (\%) & $3(6.0 \%)$ & $9(18.0 \%)$ & 0.065 (NS) \\
\hline Impacted stone, n (\%) & $4(8.0 \%)$ & $7(14.0 \%)$ & 0.082 (NS) \\
\hline
\end{tabular}

with stone migration in laser group. A finding was statistically significant $(p=0.003)$.

In regard to the stone free rate, patients in the laser group had significantly higher stone-free rate for the proximal ureteral stones 19/22 (86.4\%) in comparison to the pneumatic group 7/21 (33.3\%) $(p=0.002)$.

Moreover, 22 patients in the laser group (37.9\%) required DJ stent versus 36 patients (62.1\%) in pneumatic group, which was statistically significant $(p<0.005)$.

In term of complications, such as, mucosal injury, ureteral perforation and postoperative fever, there was no statistical significance difference between the two groups ( $p=0.543, p=0.423, p=0.643$ ) respectively. While light macroscopic hematuria was found more frequently in the pneumatic group patients (14\%) in comparison to laser group patients (2\%), a finding was statistically significant $(p=0.022)$.

On the other hand, the overall complications rate between the two groups was statistically significant $(8.0 \%$ VS 32.0\%) $p=0.003$ as shown in Table 2 .

\section{Discussion}

Developments in endourology have dramatically changed the approach to ureteral calculi and transureteric endoscopic management emerged as the procedure of choice. The invention of advanced ureteroscopes, lithotripsy devices, and other instruments has made the use of open surgery very rare [17]. A variety of lithotripters can be used through ureteroscope, pneumatic and holmium: YAG laser lithotripsies are commonly used in majority of urological centers [5].

In this study the mean duration of lithotripsy for stone fragmentations into small and removable size was shorter in pneumatic group $(7.9 \pm 2.2 \mathrm{~min})$ compared to the laser group $(14.7 \pm 2.6 \mathrm{~min})$. On the other hand, the holmium: YAG laser lithotripsy had more advantages from the aspect of operation time as our results shows that the mean operative time was shorter for laser group ( $40 \pm 26 \mathrm{~min}$ ) in comparison to pneumatic group (60 \pm 40 min). These results are inconsistent with results reported by Jeon et al., 2005; Rozzaghi et al., 2013 and Rozzaghi et al., 2011 [5] [18] [19]. These findings could be best explained by the fact that in pneumatic lithotripsy the time for stone fragmentation into removable size may be shorter than holmium: YAG lithotripsy, however, the operator has to manipulate the ureteroscope to hunt for moving stones and hence needs more time. Furthermore, pneumatic lithotripsy fragment calculi into multiple chunks that need to be basketed and removed [5]. In 
contrary, holmium: YAG lithotripsy vaporizes and de bulks the stone until one or only a few fragments remain which may be basketed easily [5]. In our study, majority of patients in the laser group stayed in hospital less than (24 hours) (38 patients 70.4\%) in comparison to only 16 patients in the pneumatic group (29.6\%) a finding was statistically significant $(p<0.002)$. This is in agreement with studies reported by Jeon et al., 2005; Rozzaghi et al., 2013 and Rozzaghi et al., 2011 [5] [18] [19].

The shorter operative time required in laser lithotripsy, less expected complications, higher immediate stone free rate, and less ureteral stent requirement may all contribute to the fact that majority of patients in the laser group needed less hospitalization.

In the present study, the immediate stone free rate of holmium: YAG laser lithotripsy was superior to that of pneumatic lithotripsy (88\% VS 62\%) respectively. These findings approach results reported by Jeon et al., 2005 and Tipu et al., 2007 in which figures of $96 \%$ for laser lithotripsy versus $71 \%$ for pneumatic lithotripsy were reported [5] [20]. While this result was in disagreement with a study conducted by Bhandri \& Basnet, 2011 in which figures of (92\% VS 94\%) for laser and pneumatic lithotripsy was reported respectively [21]. The underlying mechanism of stone fragmentation in laser lithotripters in which most calculi can be fragmented into either extractable fragments or into small sand-like particles which don't require removal is the main cause of this superiority in the immediate stone free rate in comparison to the pneumatic lithotripters [22].

Noticeably, however, we reported a lower immediate stone free rate for both laser and pneumatic group in comparison to other studies [20]-[22]. This could be explained to some extend by the fact that more than third of the ureteric stones in our cases in both groups were located in upper ureter, in which insignificant small stone fragments migrate upward during surgery and cleared spontaneously in the next few days to weeks without sequel.

On the other hand, in our study the 4 weeks stone-free rate was found in 49 patients (98\%) in laser group, while it was found in 47 patients (94.0\%) in pneumatic group. This result was statistically not significant ( $p=$ 0.0732) and was in agreement with result reported by Grasso et al., 1996; Bhandri \& Basnet, 2011 and Sun et al., 2002 [1] [21] [22].

In the current study, upward migration of Stones occurred in five patients (10\%) in pneumatic group. While, there was only one patient (2\%) with upward stone migration in laser group. A finding was statistically significant $(p=0.003)$. This finding was reported by other researchers in which retrograde stone migration occurred in $10 \%$ of pneumatic group and in $6 \%$ of laser group [21]. This could be explained by the different mechanism of lithotripter that could affect the rate of stone migration and constitutes the mechanism of failure in ureteroscopic lithotripsy. In lithoclast lithotripsy calculi are fragmented with a mechanism similar to that of pneumatic jackhammer [23]. While the mechanism of holmium: YAG energy which heats the stones to a critical thermal threshold at which the stone composition is altered yielding a stone crater and small fragments. Therefore undesired upward migration of stones or fragments can be minimized [24] [25].

Moreover, to minimize unwanted upward migration, in majority of our cases we have applied energy in a single pulse as we observed that it was more powerful in breaking stones and more helpful in preventing the stones from going upwards into the kidneys. In addition, we tried to elevate head end of the table to prevent stone up-migration.

In our study, 22 patients in the laser group (37.9\%) required ureteral stent (DJ) versus 36 patients (62.1\%) in pneumatic group, which was statistically significant $(p<0.005)$. This is in agreement with Denstedt et al., 2011, Darren Foreman and Sophie Plagakis et al., 2014 who documented that routine stenting after ureteroscopic intracorporeal lithotripsy with the holmium laser is not required as long as the procedure is uncomplicated [26] [27].

In term of complications, such as, mucosal injury, ureteral perforation and postoperative fever, there was no statistically significance difference between the two groups ( $p=0.543, p=0.423, p=0.643$ ) respectively. This in accordance with results reported by Razhahe, 2011 and Bhandari \& Basnet, 2011 [19] [21]. While hematuria was found more frequently in the pneumatic group patients (14\%) in comparison to laser group patients (2\%), a finding was statistically significant $(p=0.022)$.

On the other hand, the overall complications rate between the two groups was statistically significant $(8.0 \%$ VS 32.0\%) in laser and pneumatic group respectively $p=0.003$. This finding is in agreement with result reported by Joen et al., 2005 and Tipu et al., 2007 [5] [20]. Lithoclast lithotripsy fragmented calculi into more fragments than holmium: YAG laser lithotripsy. The increased number of fragments, basketing and manipulation of ureteroscopy seemed to increase mucosal injury, bleeding and impaired vision especially in the case of 
stone impaction [27]. Even though holmium: YAG fiber tips should be kept in contact with the stone and off the mucosa with the aid of tracer light [28].

The depth of thermal injury to the urothelium is only $(0.5$ - 1) $\mathrm{mm}$ [29] and this explains no incidence of perforation of the ureter with laser lithotripsy ( $0.0 \%)$ compared with pneumatic lithotripsy group (4.0\%).

\section{Conclusions}

Holmium: YAG laser lithotripsy was associated with shorter operation time and postoperative hospitalization period. In addition, Holmium: YAG lithotripsy is safe and more effective than (Pneumatic) lithoclast lithotripsy in the aspect of immediate stone free rate.

We believe that Holmium: YAG laser lithotripsy is an excellent treatment modality for managing ureteral calculi.

\section{References}

[1] Grasso, M. (1996) Experience with the Holmium Laser as an Endoscopic Lithotrite. Urology, 48, $199-206$. http://dx.doi.org/10.1016/S0090-4295(96)00158-6

[2] Osti, A.H., Hofmockel, G. and Frohmuller, H., (1997) Ureteroscopic Treatment of Ureteral Stones: Only An Auxiliary Measure of Extracorporeal Shoch Wave Lithotripsy or a Primary Therapeutic Option? Urologia Internationalis, 59, 177-181. http://dx.doi.org/10.1159/000283057

[3] Teichman, J.M., Rao, R.D., Rogenes, V.J. and Harris, J.M. (1997) Ureteroscopic Management of Ureteral Calculi: Electrohydraulic Versus Holmium: YAG Laser Lithotripsy. The Journal of Urology, 158, 1358-1361. http://dx.doi.org/10.1016/S0022-5347(01)64214-9

[4] Knudsen, B., Beiko, D. and Denstedt, J. (2004) Stenting after Ureteroscopy: Prosandcons. Urologic Clinics of North America, 31, 173-180.

[5] Seon, S., Jeon, J. and Kyu-Sung, L. (2005) A Comparison of Holmium: YAG Laser with Lithoclast Lithotripsy in Ureteral Calculi Fragmentation. International Journal of Urology, 12, 544-547. http://dx.doi.org/10.1111/j.1442-2042.2005.01087.x

[6] Vassar, G.J., Chan, K.F., Teichman, J.M., et al. (1999) Holmium: YAG Lithotripsy: Photothermal Mechanism. Journal of Endourology, 13, 181-190. http://dx.doi.org/10.1089/end.1999.13.181

[7] Dushinski, L., Dushinski, J.W. and Lingeman, J.E. (1998) High-Speed Photographic Evaluation of Holmium Laser. Journal of Endourology, 12, 177-181.

[8] Bader, M.J., Eisner, B., Porpiglia, F., Preminger, G.M. and Tiselius, H.G. (2012) Contemporary Management of Ureteral Stones. European Urology, 61, 764-772. http://dx.doi.org/10.1016/j.eururo.2012.01.009

[9] Devarajan, R., Ashraf, M., Beck, R.O., Lemberger, R.J. and Taylor, M.C. (1998) Holmium: YAG Lithotripsy of Ureteric Calculi; an Experience of 300 Procedures. British Journal of Urology, 82, 342-347. http://dx.doi.org/10.1046/j.1464-410X.1998.00754.x

[10] Breda, A., Ogunyemi, O., Leppert, J.T., et al. (2008) Flexible Ureteroscopy and Laser Lithotripsy for Single Intrarenal Stone $2 \mathrm{~cm}$ or Greater Is This a New Frontier? The Journal of Urology, 179, 981-984. http://dx.doi.org/10.1016/j.juro.2007.10.083

[11] Calvano, C.J., Moran, M.E., White, M.D., et al. (1999) Experimental Utilization of the Holmium Laser in a Model of Ureteroscopic Lithotripsy: Energyanalysis. Journal of Endourology, 13, 113-115. http://dx.doi.org/10.1089/end.1999.13.113

[12] Scarpa, R.M., De Lisa, A., Porru, D. and Usai, E. (1999) HO: YAG Laser Ureterolithotripsy. European Urology, 35, 233-238. http://dx.doi.org/10.1159/000019852

[13] Aghamir, S.K., Mohseni, M.G. and Ardestani, A. (2003) Treatment of Ureteral Calculi with Ballistic Lithotripsy. Journal of Endourology, 17, 887-890. http://dx.doi.org/10.1089/089277903772036208

[14] Denstedt, J.D., Eberwein, P.M. and Singh, R.R. (1992) The Swiss Lithoclast: A New Device for Intracorporeal Lithotripsy. Journal of Endourology, 148, 1088-1090.

[15] Elganainy, E., Hameed, D.A., Elgammal, M., Abd-Elsayed, A.A. and Shalaby, M. (2009) Experience with Impacted Upper Ureteral Stones;Should We Abandon Using Semi-Rigid Ureteroscopes and Pneumatic Lithoclast? International Archives of Medicine, 2, 13-17. http://dx.doi.org/10.1186/1755-7682-2-13

[16] Tan, P.K., Tan, S.M. and Consigliere, D. (1998) Ureteroscopic Lithoclast Lithotripsy: A Cost-Effective Option. Journal of Endourology, 12, 341. http://dx.doi.org/10.1089/end.1998.12.341

[17] Aridogan, A., Zeren, S. and Bayazit, Y. (2005) Complications of Pneumatic Ureterolithotripsy in the Early 
Post-Operative Period. Journal of Endourology, 19, 50-53. http://dx.doi.org/10.1089/end.2005.19.50

[18] Razzaghi, M.R., Razi, A., Mazloomfard, M.M., Taklimi, A.G., Valipour, R. and Razzaghi, Z. (2013) Safety and Efficacy of Pneumatic Lithotripter versus Holmium Laser in Management of Ureteral Calcui. Urology Journal, 10, $762-$ 766.

[19] Razaghi, M., Razi, A., Mazloomfard, M.M., Mokhtarpour, H., Javanmard, B. and Mohammadi, R. (2011) TransUreterolithotripsy of Ureteral Calculi: Which Is the Best; Pneumatic or Holmium Laser Technique? Journal of Lasers in Medical Sciences, 2, 59-62.

[20] Tipu, S.A., Malik, H.A., Mohhayuddin, N., Sultan, G., Hussain, M., Hashmi, A., et al. (2007) Treatment of Ureteric Calculi-Use of Holmium: YAG Laser Lithotripsy versus Pneumatic Lithoclast. JPMA, 57, 440-443.

[21] Bhandari, B.B. and Basnet, R.B. (2011) Comparison of Holmium Laser and Pneumatic Lithotripsy in Treatment of Ureteral Stones. JGPEMN, 17-20.

[22] Sandhu, A.S., Srivastava, A., Madhusoodanan, P., et al. (2007) Holmium: YAG Laser for Intra Corporeal Lithotripsy. MJAFI, 63, 48-51.

[23] Sun, Y., Wang, L., Liao, G., Xu, C., Yang, Q. and Qian, S. (2002) Pneumatic Lithotripsy versus Laser Lithotripsy in the Endoscopic Treatment of Ureteric Calculi. Journal of Endourology, 15, 587-588. http://dx.doi.org/10.1089/089277901750426346

[24] Menon, M., Parulkar, B.C., Drash, G.W., et al. (2007) Urinary Lithiasis: Etiology, Diagnosis, and Management. In: Walsh, P.C., Ed., Campbell's Urology, 9th Edition, Saunders, Philadelphia, 2661-2733.

[25] Teichman, J.M., Vassar, G.J., Bishoff, J.T. and Bellman, G.C. (1998) Holmium: YAG Lithotripsy Yields Smaller Fragments than Lithoclast, Pulsed Dye Laser or Electrohydraulic Lithotripsy. The Journal of Urology, 159, 17-23. http://dx.doi.org/10.1016/S0022-5347(01)63998-3

[26] Denstedt, J., Wollin, T., Sofer, M., Nott, L., Weir, M. and Honey, J. (2011) A Prospective Randomized Controlled Trial Comparing Non-Stented versus Stented Ureteroscopic Lithotripsy. The Journal of Urology, 165, 1419-1422. http://dx.doi.org/10.1016/S0022-5347(05)66320-3

[27] Foreman, D. and Plagakis, S., Fuller, A.T. (2014) Should We Routinely Stent after Ureteropyeloscopy? Department of Urology, Royal Adelaide Hospital, Adelaide. BJUI.

[28] Segura, J.W., Preminger, G.M., Assimos, D.G., Dretler, S.P., Kahn, R.I. and Macluso, J.N. (1997) Ureteral Stones Clinical Guidelines Panel Summary Report on the Management of Ureteral Calculi. The Journal of Urology, 158, 1915-1921. http://dx.doi.org/10.1016/S0022-5347(01)64173-9

[29] Beaghler, M., Poon, M., Ruckle, H., Stewart, S. and Wei, D. (1998) Complications Employing the Holmium: YAG Laser. Journal of Endourology, 12, 533-555. http://dx.doi.org/10.1089/end.1998.12.533 